Bull. Fac. Agric., Cairo Univ., 70:179-186 (2019).

\title{
USE THE ALMON MODEL TO MEASURE THE EFFECT OF WATERMELON SUPPLY ON IT'S PRICE CHANGES
}

(Received: 22.7.2019)

\author{
By \\ M. M. H. Mileek \\ Department of Agricultural Production Economics - Agricultural Economics Research Institute - \\ Agricultural Research Center - Giza - Egypt.
}

\begin{abstract}
The objective of this research was to analyze and estimate the farmer's response to some important economic variables such as farm prices during the period (2005-2016) to identify the most important factors affecting the crop production. Also to estimate the degree of farmers response, the time required to respond and elasticity supply response in the short and long runs. To achieve the research goal, the descriptive and quantitative analysis methods used were suitable for measuring the supply response, Supply Response Impact. The research was based on data published by the Department of Economic Affairs, Central Department of Agricultural Economics, (in Arabic) in the Ministry of Agriculture and Land Reclamation, Egypt in addition to the published researches and the Arab and foreign scientific literature related to the research subject as well as the websites. The results showed the significance annual increase in the form price of the water melon crops (pound per ton) and some of the competing vegetable crops in the production season such as melon, Shahad, cantaloupe, and pumpkin. The annual increase in lag area of the watermelon crops and the lag area for competing crops was insignificant, indicating the stability of their averages. The estimated results of the Almon model showed a decrease in the value of elasticity coefficients in the short term, estimated at $0.40 \%$, $0.08 \%, 0.71 \%, 0.62 \%$ and $0.32 \%$ for watermelon, melon, Shahad, cantaloupe, pumpkin respectively. While in the long term the elasticity was about $0.51 \%, 0.10 \%, 0.90 \%, 0.79 \%$ and $0.48 \%$, respectively. The annual response rate was estimated to be about 0.78 (9.4 months), while the full response period was about 1.3 years, indicating a decrease in the supply response period for watermelon crops. This may be due to the possibility of expanding the area planted with watermelon after a year. The study recommends the need to expand horizontally and vertically in the cultivation of watermelon crops, and horizontal expansion by growing more new land with watermelon to increase production and increase market supply to reduce the price. Vertical expansion will increase the production of the unit area and increase the quality of production and introduce new early harvest varieties and types of watermelon.
\end{abstract}

Key words: Supply Response, Elasticity Supply Response in Short Run, Elasticity supply Response in Long Run, Supply Response Period.

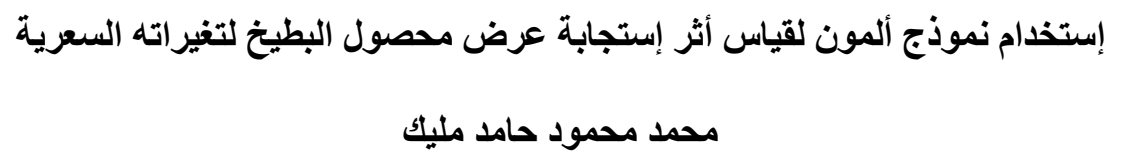

$$
\text { معهد بحوث الإقتصاد الزراعي ـ مركز البحوث الزر اعية ـ الجيزة ـ مصر }
$$

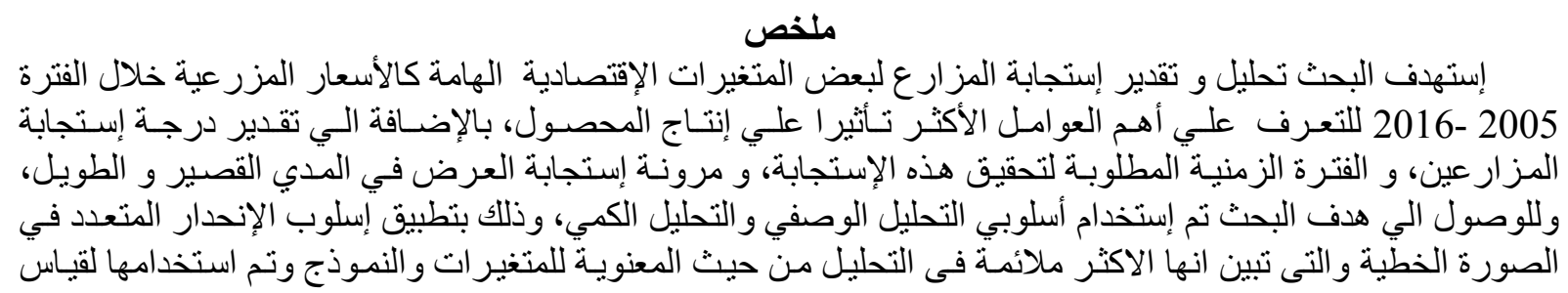




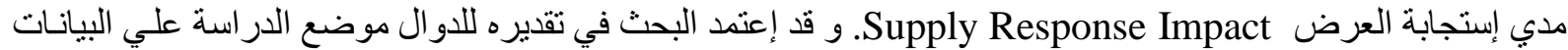

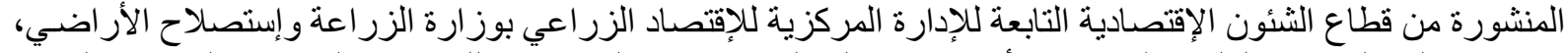

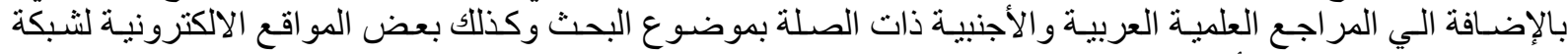

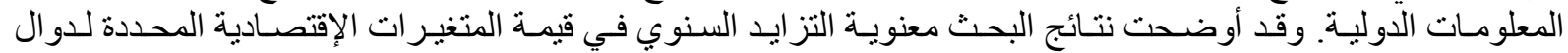

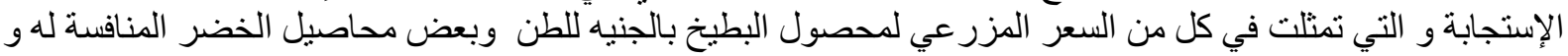

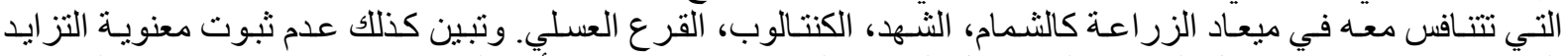

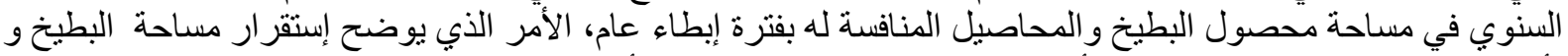

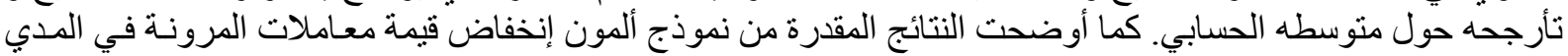

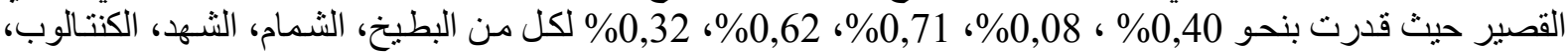

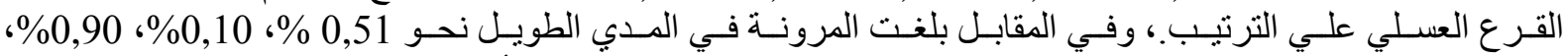

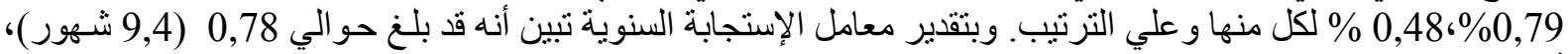

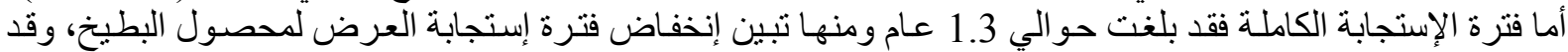

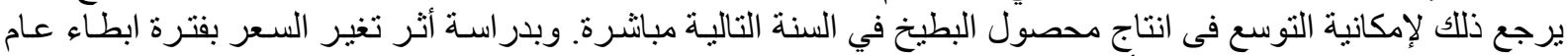

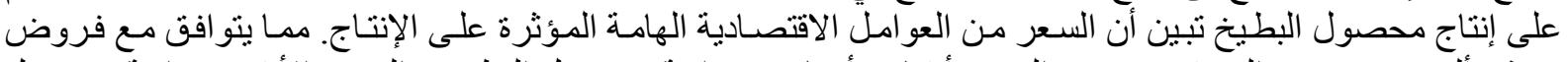

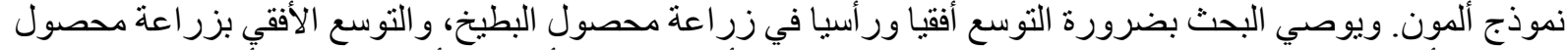

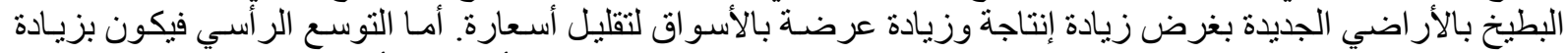

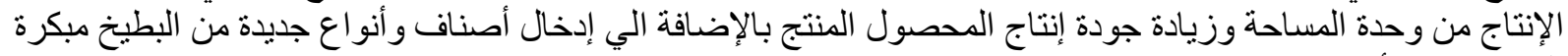

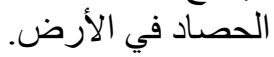

\section{3. الهوف من البحث}

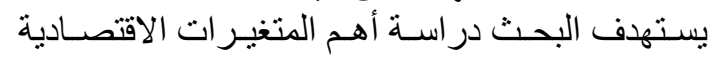

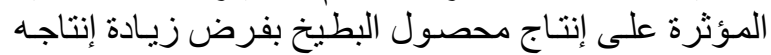

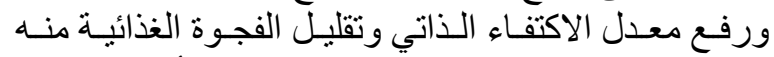
بالإضافة إلى زيادة عرضه وباه ولالتالي انخفاض أسعاره.

\section{4. الطريقة البحثية}

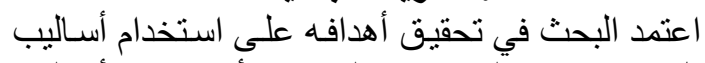

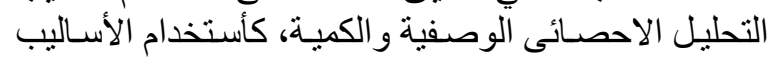

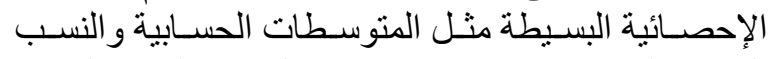

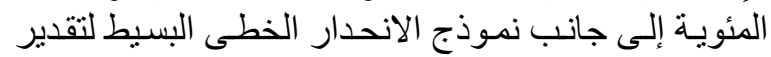

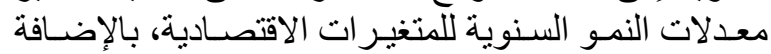

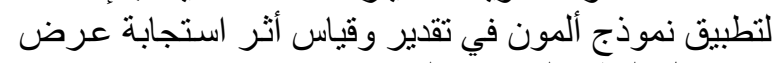
محصول البطيخ لتغير اته السعرية.

\section{5 5 5 البادر البيانات}

إعتمد البحث على البيانـات الثانويـة المنشـورة و التئي

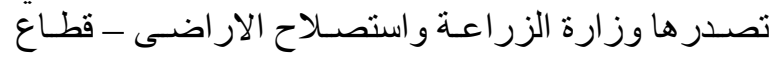

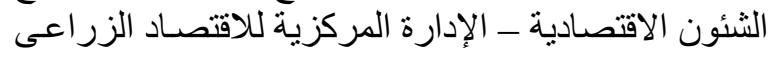

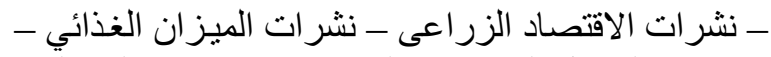

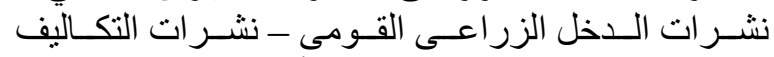

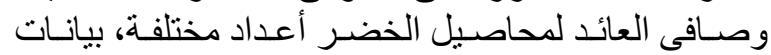

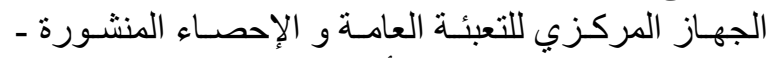

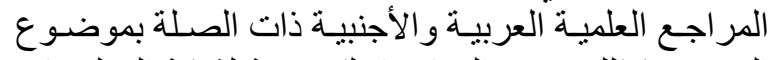

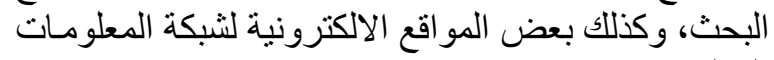
الدولية (الانترنت). - اكلت بعض.

\section{6. النتائج البحثية}

تبين من بيانات جدول 1، 2 الأتىى:

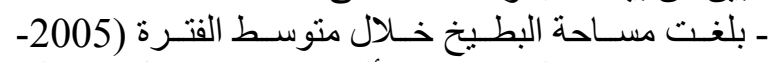

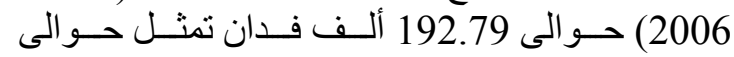

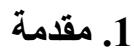

يعتبر محصول البطيخ من محاصيل الخضر الصيفية

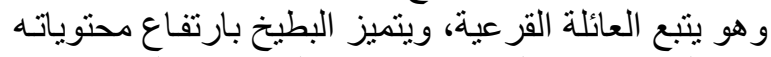

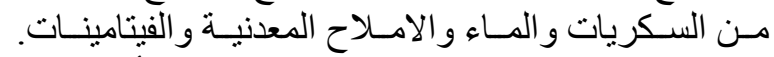
ويزر عن البطيخ في كثير من دول العـالم العيث حيث أكثر دول

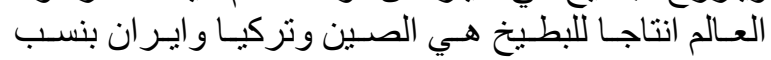

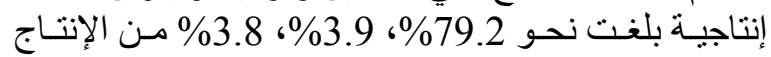

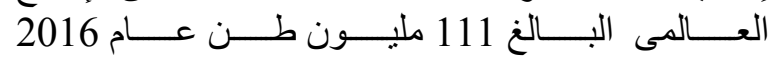
(Wikipedia.org, 2016)

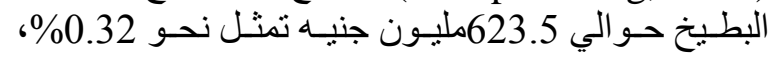

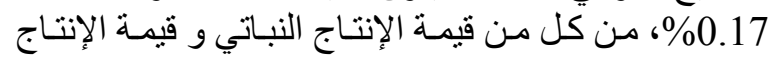

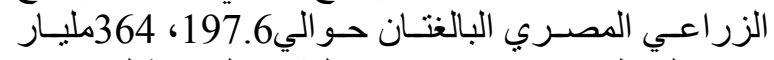
جنيه علي الترتيب عَام 2016. (النشرة السنوية النية لتقديرات

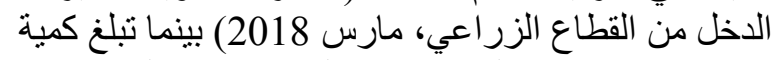

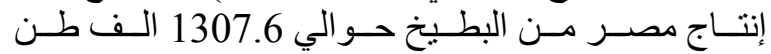

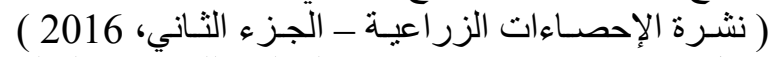

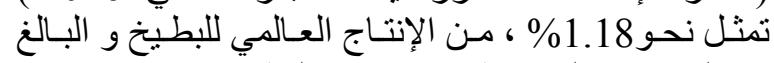

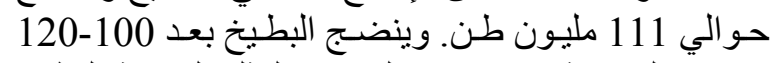

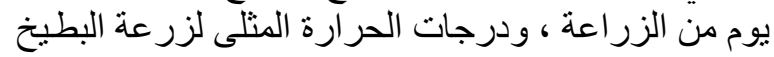

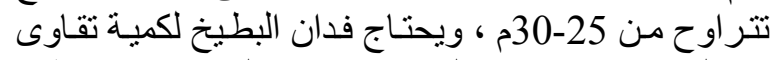

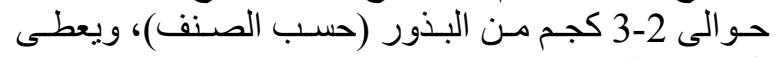
الفدان حو الى 1500-2000 ثمرة.

\section{2. - 2. - 2 المشكلة البحثية}

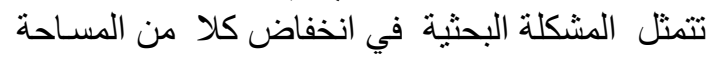

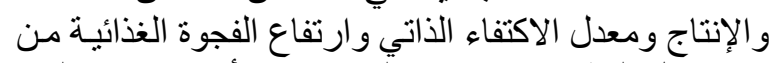

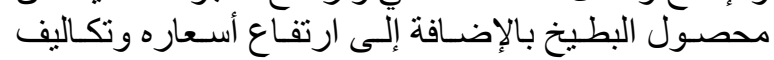

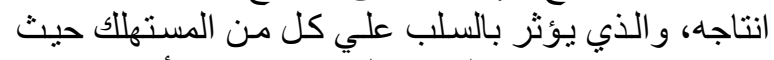

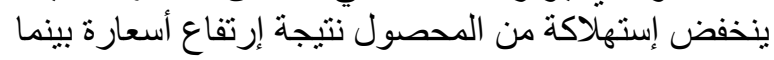
يتمثل ضرر المنتج في إرتفاع تكاليف الإنتاج. 


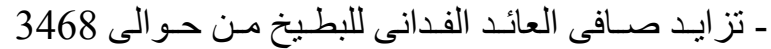

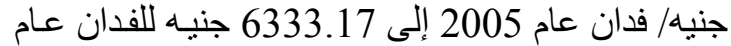

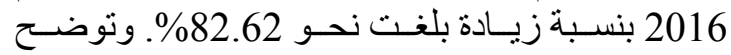

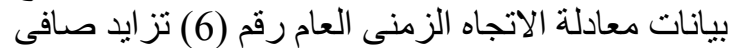

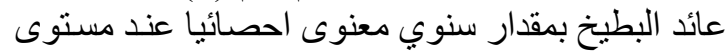
معنوية 1\% بلغ حو الى الى 611.52 جنيه للفدان.

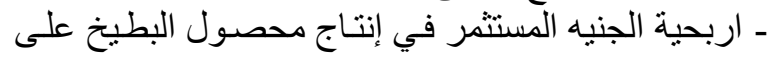

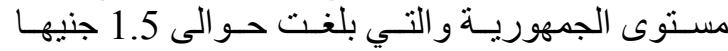

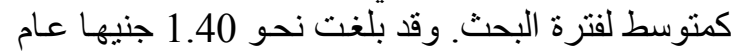

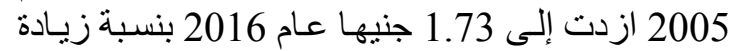
بلغت 23.57\%. وقد أخذت إربحية الجنيه المستثمر في إنيا

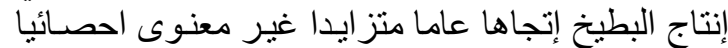
عند مستوى 5\% خلال فترة البحث مما يبين الإسئ الاستقرار النسبى لاربحية الجنيه المستثمر حول منوسطه الحست الحسابى

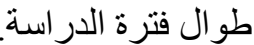

1.6. دالة استجابة العرض لمحصول النية البطيخ

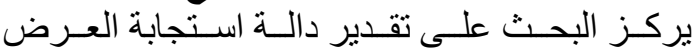

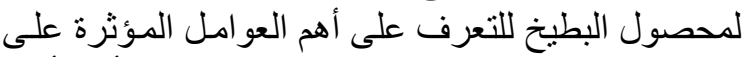

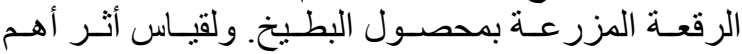

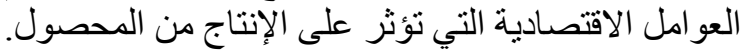

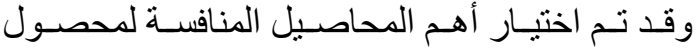

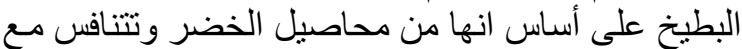

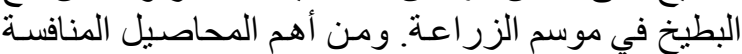

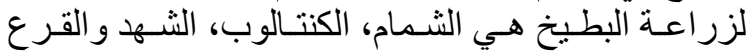

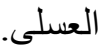

ثم استخدام نموذج ألمون لبيـان مدى استجابة انتـاج

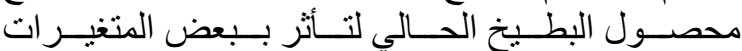

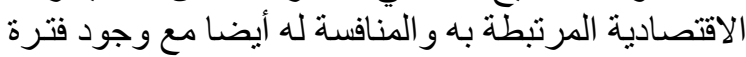

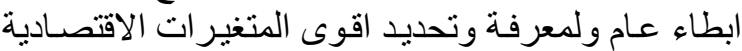

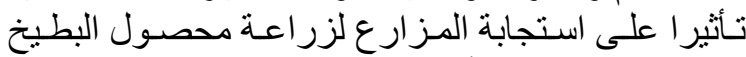

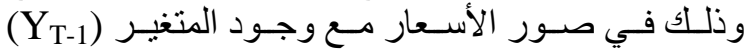

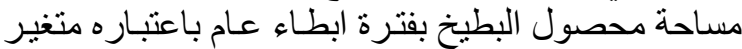
اساسى ليتم التقدير باستخدام نموذج البن ألمون.

نموذج ألمون Almon لاستجابة العرض (Johnston, 1960) $\mathrm{Y}_{\mathrm{t}}=\beta_{0} \mathrm{X}_{\mathrm{t}}+\beta_{1} \mathrm{X}_{\mathrm{t}-1}+\ldots .+\beta_{5} \mathrm{X}_{\mathrm{t}-\mathrm{s}}+\mu_{\mathrm{t}}$

$\mathrm{Yt}=\propto+\beta \mathrm{X}_{\mathrm{t}-0}+\mu_{\mathrm{t}}$

المتغير التابع في العام الحسالى T T الإنتاج في العام

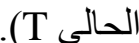

= المتغير المستقل في العام الحسالى T T السعر في العام

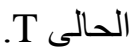

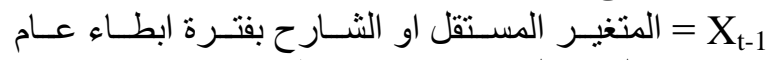
(السعر المزرعى/ بفترة ابطاء عام).

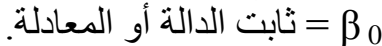
㳊 $=\beta \propto$ 年 =S

المتغير التابع دالة في المتغير المستقل بفترة ابطاء عام

$$
\begin{array}{r}
Y_{t}=f\left(X_{t}-0\right) \\
\text { الزمناع }=T
\end{array}
$$

23.20\% من منوسط إجمالي مسـاحة و إنتاج الخضـر

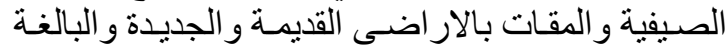
حو الى 830.9 ألف فدان.

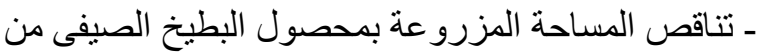

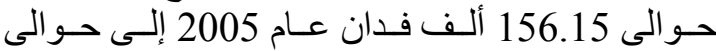
107.42 ألف فدان عام 2016 بنسبة تناقص بلغت نحو الإنى

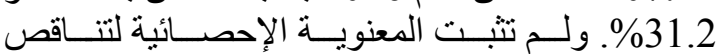

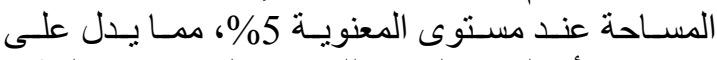

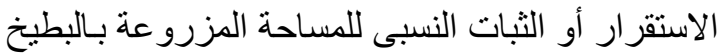
حول متوسطها الحسابى.

ـ تناقص الإنتاج الكلى من 1733.7 ألف طن عـام 2005

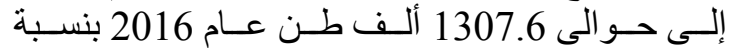

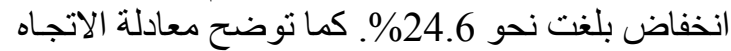

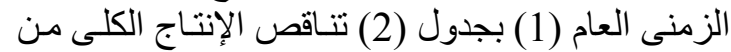

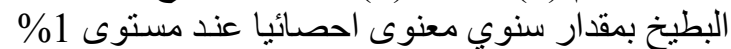

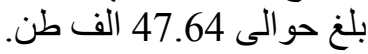

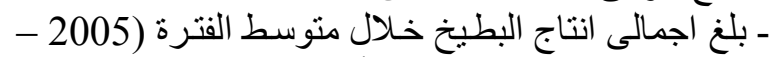

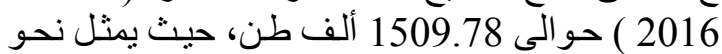
16.57 \% من منوسط اجمـالى انتـاج الخضـر الصيفية و المقات بالار اضى القديمة و الجديدة و البالغ حو الى 9.1

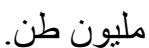
ـ تناقص الاستهلاك الكلى من 1866 ألف طن عام 2016 الف 2005

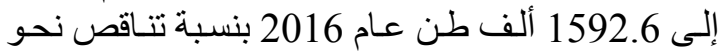
14.65\%. و واخذ الاستهلاك الكلى مـن البطيخ اتجاهـا عاما متناقصـا غير معنوى احصـائيا خـلال فترة البحثي.

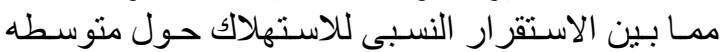

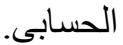
ـ تزايدت الفجوة الغذائية من البطيخ من 132.26 ألف طن

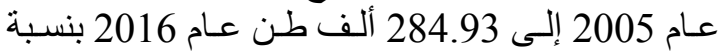

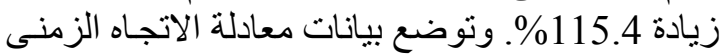

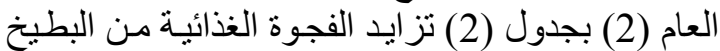

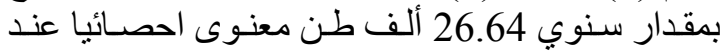
مستوى 1\%.

ـ انخفضت النسبة المئويـة للاكتفاء الذاتي من البطيخ من

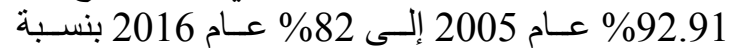
انخفاض 11.62\%. كمـا توضح بيانـات معادلة الاتجاه

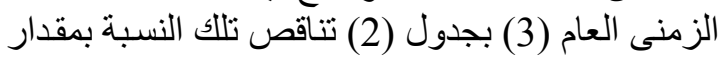

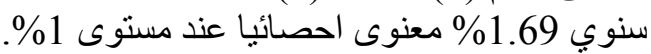

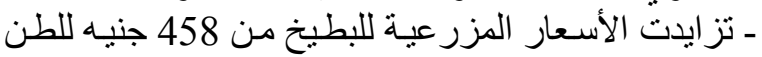

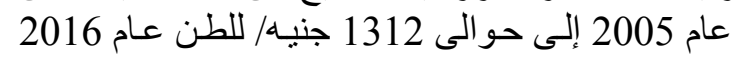

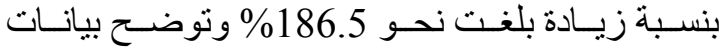

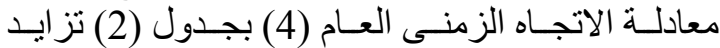

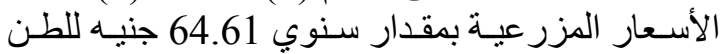

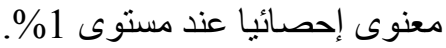
ـ تز ايد اجمالى التكاليف الفدانية من 2477 جنيه للفدان عام

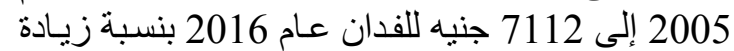

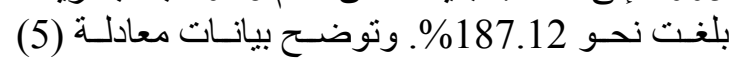

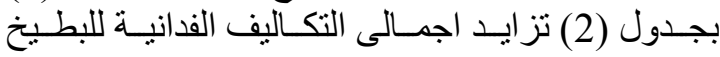

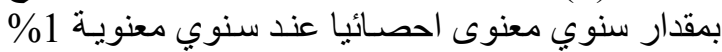
بلغ حو الى 334.56 جنيه للفدان. 


\begin{tabular}{|c|c|c|c|c|c|c|c|c|c|c|c|}
\hline الإنتاج بالالف طن & بالالف فـاحةن & الجنتيمية & صنية/فذان العائد & جنيه/فاليفان & جنيه/طن & الناكتبة المئوية & بالالف طذائية & بالالف طن(2) & $\begin{array}{l}\text { بالالفتاج } \\
\text { طان(1) }\end{array}$ & بالالف فدان(1) & السنوات \\
\hline 8886.20 & 843.08 & 1.40 & 3468 & 2477 & 458 & 92.61 & 132.26 & 1866 & 1733.74 & 156.15 & 2005 \\
\hline 9701.08 & 892.68 & 1.38 & 3842 & 2794 & 471 & 96.58 & 68.75 & 2009 & 1940.25 & 157.16 & 2006 \\
\hline 9308.78 & 852.34 & 1.28 & 4832 & 3764 & 618 & 99.07 & 13.73 & 1471 & 1457.27 & 115.70 & 2008 \\
\hline 9143.71 & 811.26 & 1.21 & 4418 & 363.8 & 644 & 86.23 & 225.23 & 1636 & 1410.78 & 113.83 & 2009 \\
\hline 9193.90 & 807.66 & 1.26 & 5144 & 4070 & 697 & 86.66 & 215.56 & 1616 & 1400.44 & 104.17 & 2010 \\
\hline 8541.62 & 767.18 & 1.36 & 5805 & 4268 & 764 & 85.01 & 223.03 & 1488 & 1264.97 & 971.68 & 2011 \\
\hline 8329.43 & 759.68 & 1.25 & 6715 & 5380 & 927 & 77.76 & 330.02 & 1484 & 1153.98 & 83.68 & 2015 \\
\hline 8039.36 & 715.35 & 1.73 & 12294 & 7122 & 1312 & 82.11 & 284.93 & 1592.55 & 1307.62 & 107.42 & 2016 \\
\hline 9113.27 & 830.90 & 1.49 & 6333.17 & 420067 & 758.83 & $* * 87.84$ & 198.26 & 1708.05 & 1509.78 & 192.79 & المتوسط \\
\hline
\end{tabular}

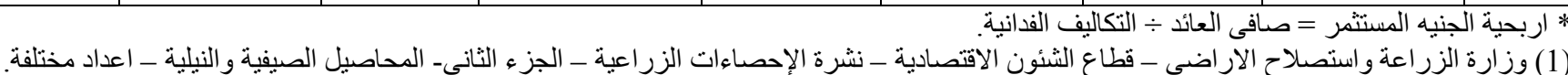

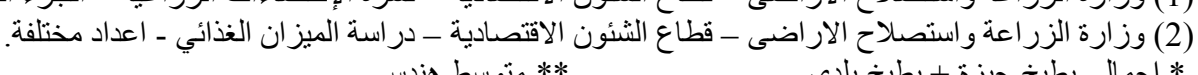


جدول (2): معادلات الاتجاه الزمنى العام لتطور أهم المتغيرات الاقتصادية لمحصول البطيخ خلال الفترة (2005-2016).

\begin{tabular}{|c|c|c|c|c|c|c|c|c|c|c|}
\hline $\begin{array}{c}\text { معدل التغير السنوي } \\
\text { (b^^ -X)*100 }\end{array}$ & المتوسط & $\mathbf{F}$ & $\mathbf{R}^{-2}$ & $\mathbf{T}$ & $\mathbf{b}^{\wedge}$ & $\mathbf{a}$ & المعنوية & الوحدة & (المتغير التابع) & رقم المعادلة \\
\hline $3.16^{-}$ & 1509.68 & 8.40 & 0.46 & $2.9-$ & $47.64-$ & 1819.46 & $\% 1$ & بالالف طن & انتاج البطيخ & 1 \\
\hline 13.44 & 198.26 & 26.19 & 0.70 & 5.12 & 26.64 & 25.1 & $\% 1$ & بالالف طن & الفجوة الغذائية في البطيخ بالالف & 2 \\
\hline $1.92-$ & 87.84 & 27.95 & 0.71 & $\begin{array}{c}- \\
5.29\end{array}$ & $1.69-$ & 99.05 & $\% 1$ & $\%$ & \% للاكتقاء الذاتي & 3 \\
\hline 8.51 & 758.83 & 90.73 & 0.89 & 9.53 & 64.61 & 338.88 & $\% 1$ & جنيه للطن & الأسعار المزرعية للبطيخ & 4 \\
\hline 7.96 & 4200.67 & 84.09 & 0.88 & 9.17 & 334.56 & 2026.03 & $\% 1$ & جنيه/فدان & اجمالى التكاليف الغذائية & 5 \\
\hline 9.66 & 6333.17 & 30.83 & 0.73 & 5.55 & 611.52 & 235.3 & $\% 1$ & جنيه/فدان & صافى العائد الفدانى للبطيخ & 6 \\
\hline
\end{tabular}




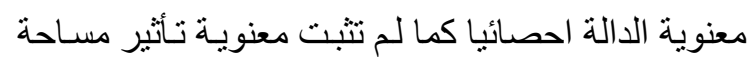

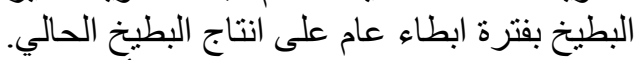

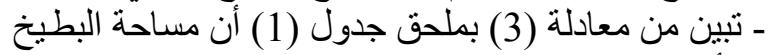

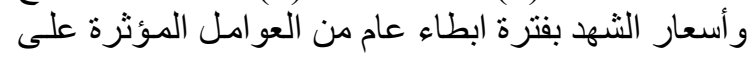

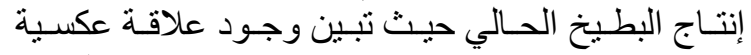

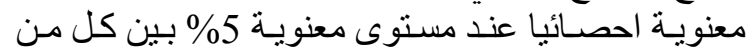

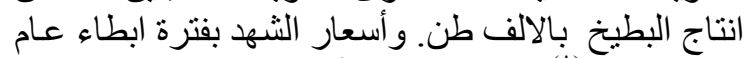

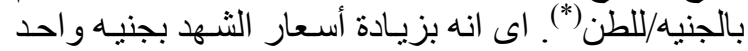

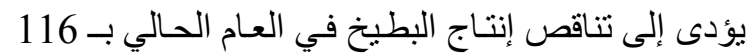

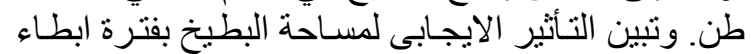

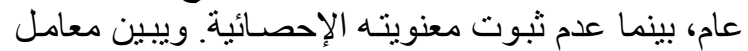

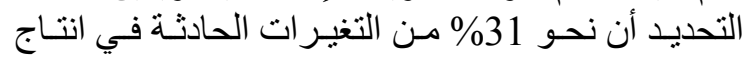

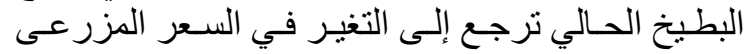

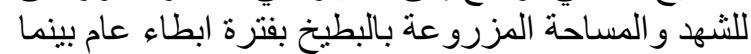

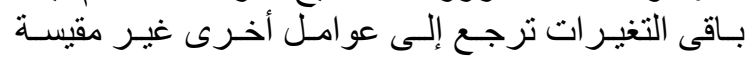

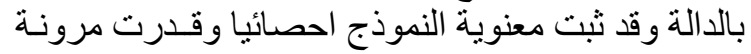

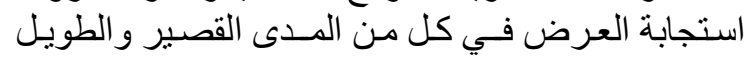

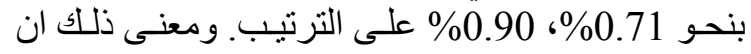

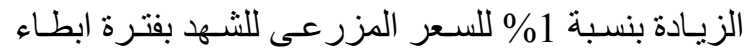

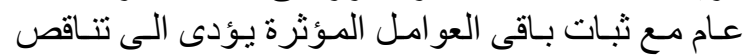

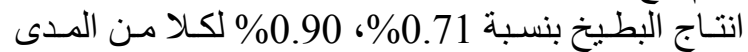

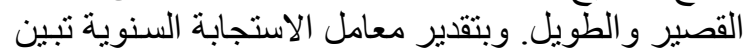

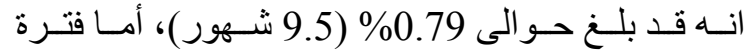

الاستجابة الكاملة فقد بلغت حو الى 1.2 سنة.

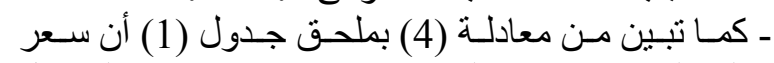

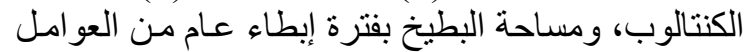

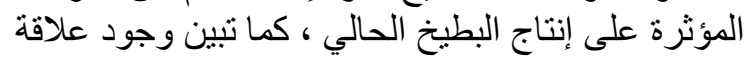

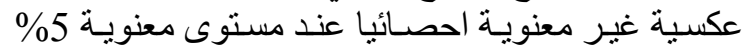

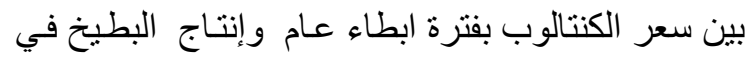

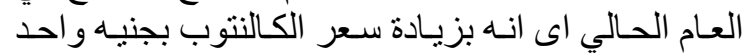

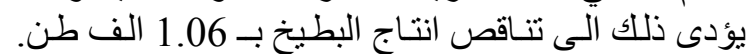

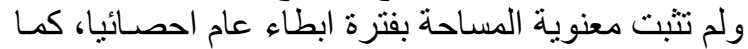
لم تنثبت معنوية الدالة احصائيا.

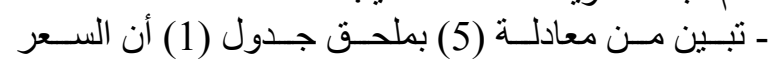

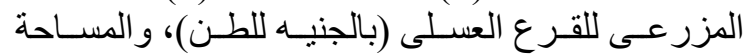

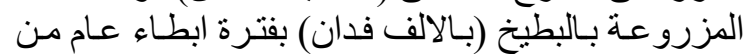

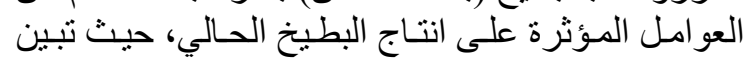

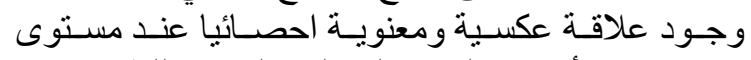

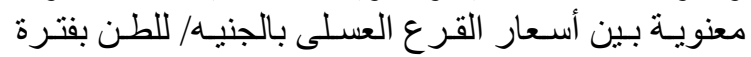

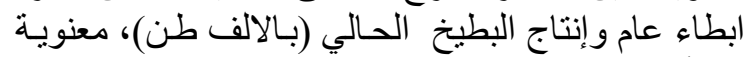
بين أسعار

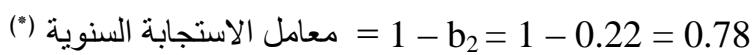

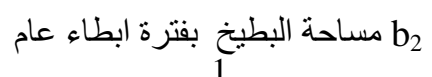

فترة الاستجابة الكاملة = $1.3=\overline{~ م ع ا م ل ~ ا ل ا س ت ج ا ب ة ~ ا ل س ن و ي ة ~}$
يفترض نموذج ألمون توزيع ب ب طبيعيا فلا يوجد ارتباط

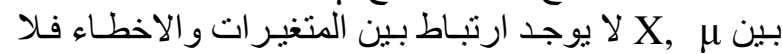

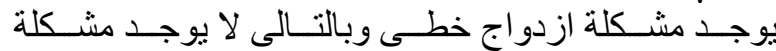
Auto correlation متحيز.

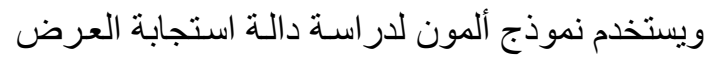

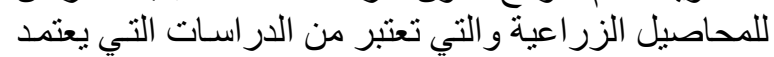

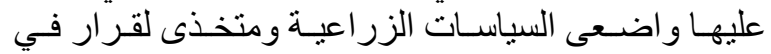

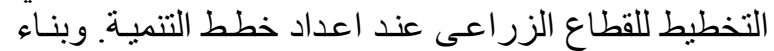

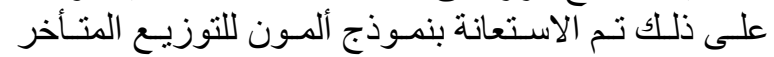

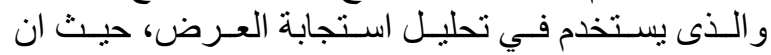

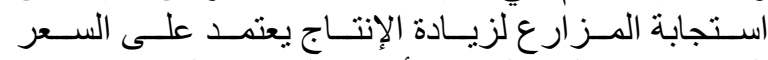
المزرعى في العام السابق وأسعار السنواتئ السات السابقة.

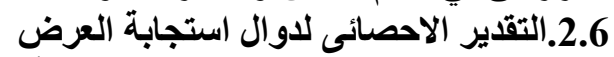

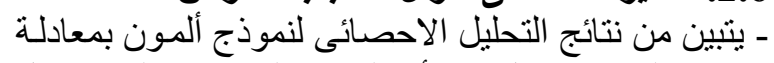

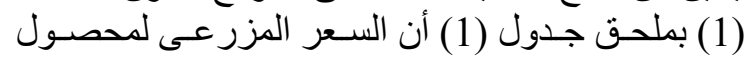

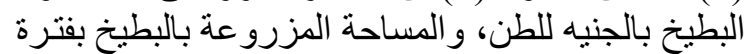

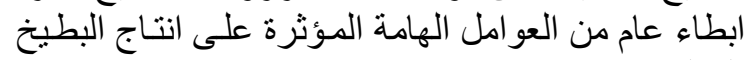

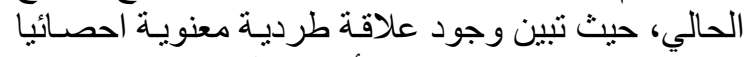
عند مستوى معنوية 5\% بين والين أسعار البطيخ بفترة ابطاء

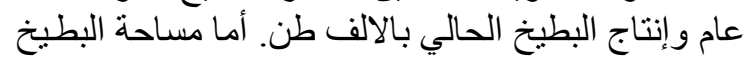

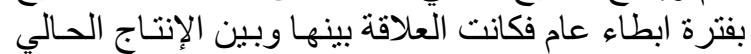

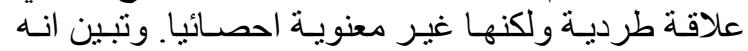

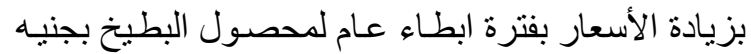

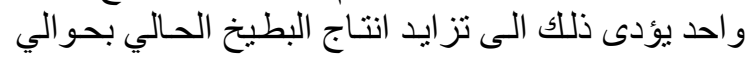

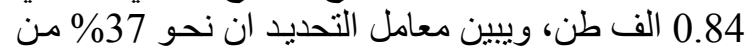

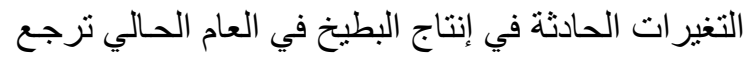

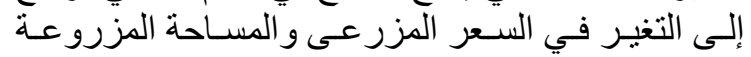

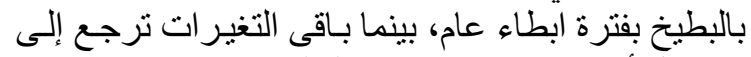

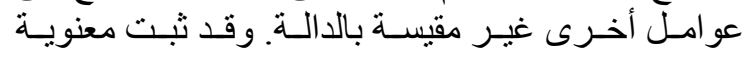
النموذج احصائيا وقدرت مرونة استجابة العرض في في كل

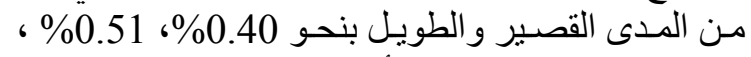

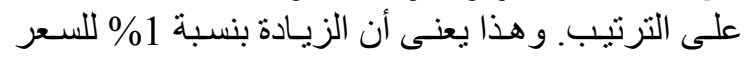

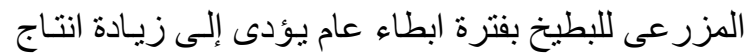

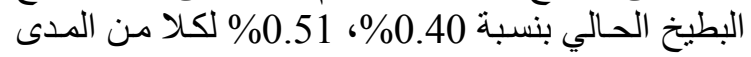

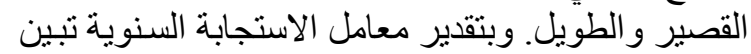

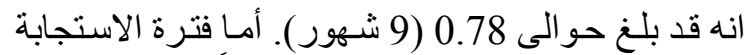

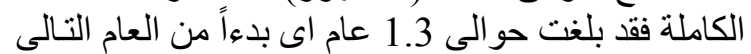

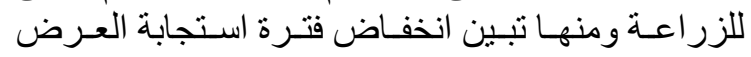

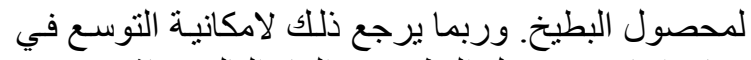

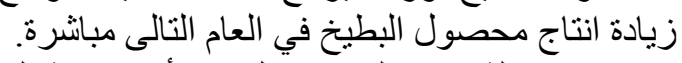

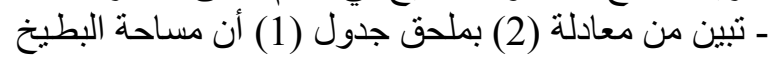

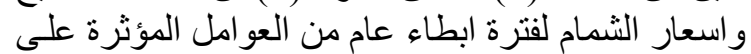

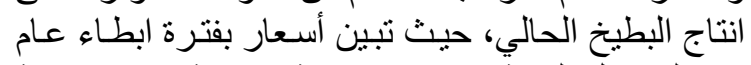

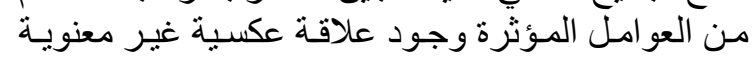

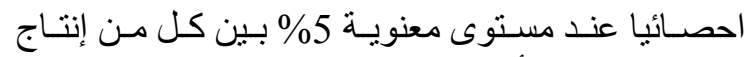

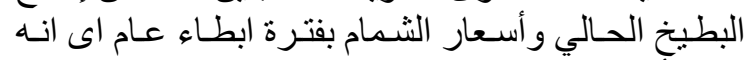

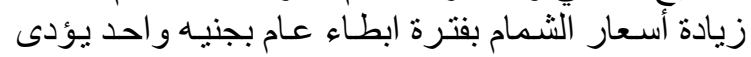
إلى تناقص انتاج البطيخ الحسالي بـ 130 طن. ولم تثنبت ئت 
ملحق جدول (1): التحليل الاحصائي لنموذج ألمون لمحصول البطيخ والمحاصيل المنافسة له.

\begin{tabular}{|c|c|c|c|c|c|}
\hline $\mathbf{F}$ & $\mathbf{R}^{2}$ & $\mathbf{R}^{2}$ & المعادلة & المتغير التابع & رقم المعادلة \\
\hline 0.37 & -0.13 & 0.08 & $\begin{aligned} & \mathrm{Y}^{\wedge}=1602.48+0.18 \mathrm{~A}_{\mathrm{t}-1}-0.13 \mathrm{P}_{2 \mathrm{t}-1} \\
&(0.54)(-0.61)\end{aligned}$ & 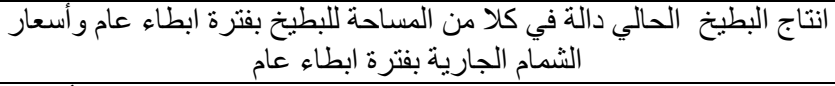 & (2) \\
\hline 1.18 & 0.03 & 0.21 & $\begin{array}{r}\mathrm{Y}^{\wedge}=537.9+0.22 \mathrm{~A}_{\mathrm{t}-1}-1.16 \mathrm{P}_{4 \mathrm{t}-1} \\
(0.72)(-1.39)\end{array}$ & انتاج البطيخ الحالي دالة في كلا من المساحة للبطيخ البطاء بفترة ابطاء عام وأسعار & (4) \\
\hline 2.98 & 0.27 & 0.40 & $\begin{array}{r}\mathrm{Y}^{\wedge}=693.92+0.34 \mathrm{~A}_{\mathrm{t}-1}-1.16 \mathrm{P}_{5 \mathrm{t}-1} \\
(1.25)\end{array}$ & 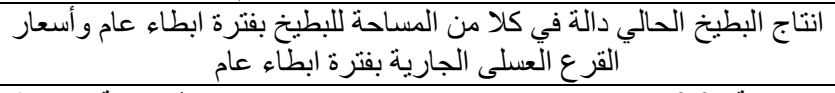 & (5) \\
\hline
\end{tabular}

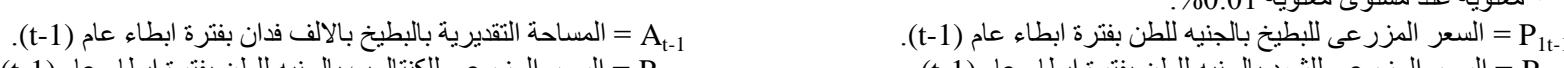
P = P4t-1 السعر المزرعى للكنتالوب بالجنبه للطن بفترة ابطاء عام (t-1).

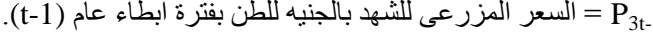

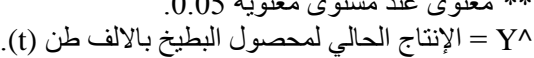

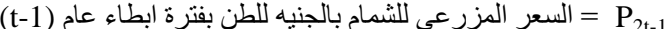

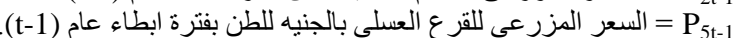

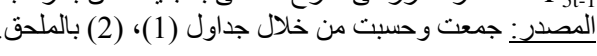

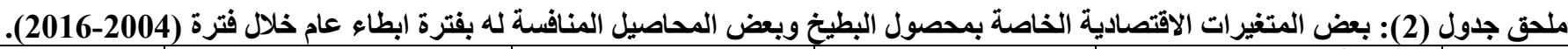

\begin{tabular}{|c|c|c|c|c|c|c|}
\hline سعر القرع العسلى جنيه/للطن & سعر الكنتالوب جنيه/للطن & سعر الشهر جنيه/للطن & سعر الشمام جنيه/للطن & سعر البطيخ جنيه/للطن & مساحة البطيخ بالالف فدان & السنوات \\
\hline 1799.1 & 903.5 & 800 & 793.9 & 763.82 & 139.80 & 2004 \\
\hline 1790 & 971.92 & 800 & 793 & 458 & 156.15 & 2005 \\
\hline 1810 & 1036 & 800 & 830 & 471 & 157.16 & 2006 \\
\hline 1900 & 650 & 850 & 872 & 517 & 148.87 & 2007 \\
\hline 2000 & 786 & 890 & 916 & 618 & 115.70 & 2008 \\
\hline 1540 & 824 & 900 & 2168 & 644 & 113.83 & 2009 \\
\hline 930 & 843 & 920 & 770 & 697 & 104.17 & 2010 \\
\hline 980 & 861 & 960 & 880.38 & 764 & 971.68 & 2011 \\
\hline 1020 & 887 & 1000 & 907.84 & 883 & 128.32 & 2012 \\
\hline 1060 & 898 & 1150 & 926.26 & 900 & 87.32 & 2013 \\
\hline 880 & 906 & 1050 & 936.44 & 915 & 139.23 & 2014 \\
\hline 920 & 963 & 1045 & 952.21 & 927 & 83.68 & 2015 \\
\hline 260 & 1248 & 1040 & 1000.01 & 1312 & 107.42 & 2016 \\
\hline
\end{tabular}

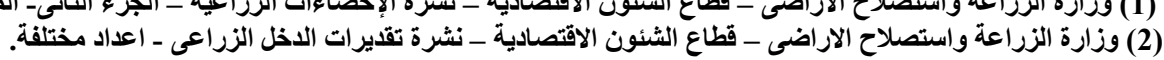




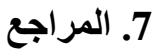

النشرة السنوية لتقديرات الدخل من القطاع الزراعي (2016).الجهاز المركزي للتعبئة العامة و الإحصاء، التراعي

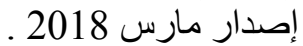

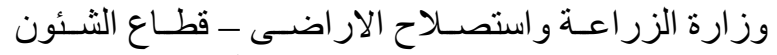

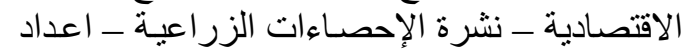
مختلفة (2016 ).

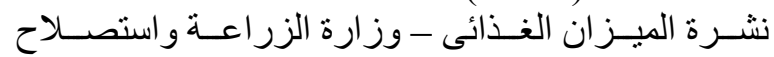

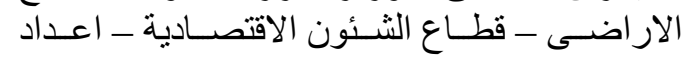
مختلفة (2016 ).

نشرة الدخل الزراعى القومى- وزارة الزر اعة واستصلاح

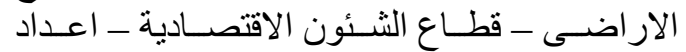
مختلفة (2016) مافكافي

نشرة التكاليف وصافى العائد - وزارة الزراعة الأفو واستصلاح

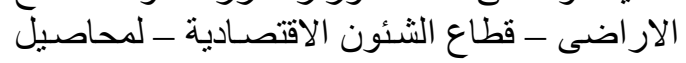

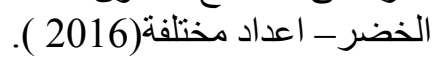

https: // Wikipedia.org ( 2016).

Johnston J.(1960). Econometric Methods, $2^{\text {nd }}$ Edition international student Edition, Mcgraw - Hill, International Book Company, New York, USA, P. 292: 294.

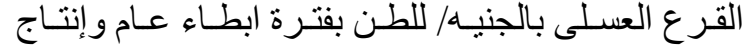

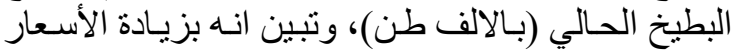

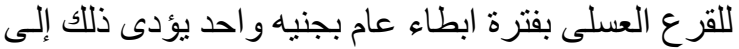

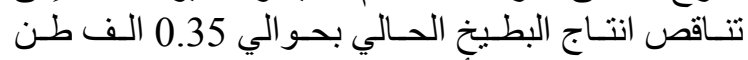

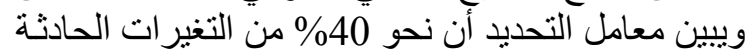

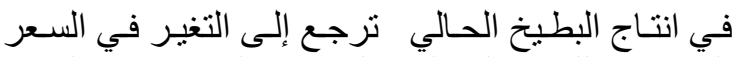

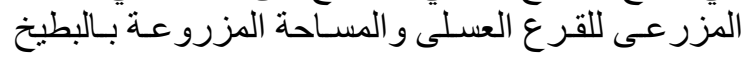

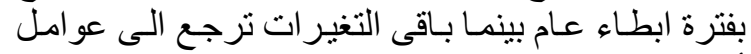

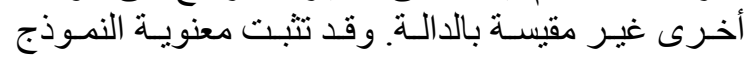

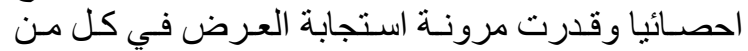

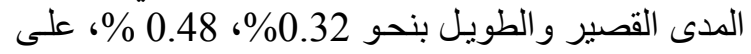

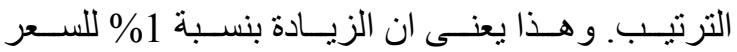

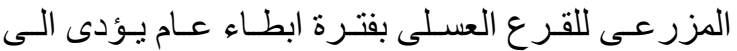

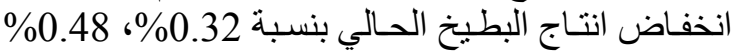

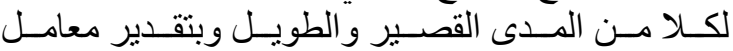

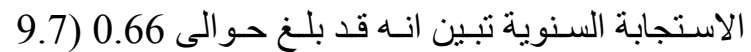

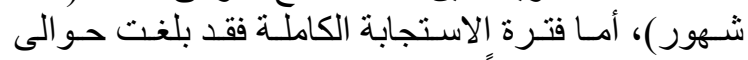

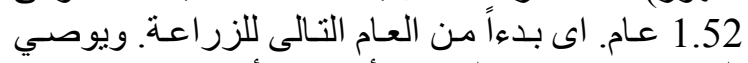

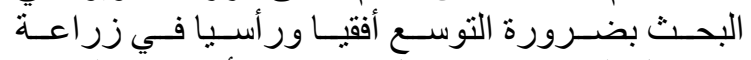

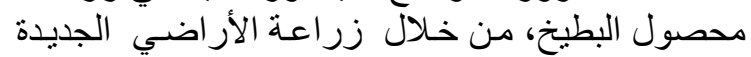

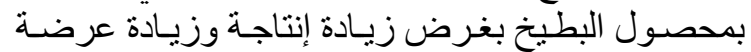

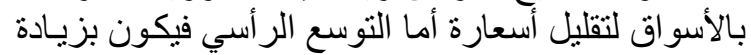

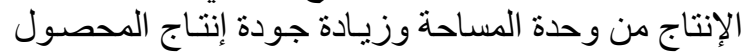

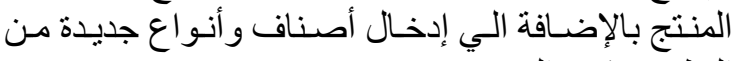

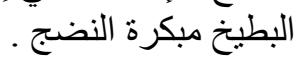

